\title{
Aeroacoustic Investigations of a Leading Edge Slat by means of the Causality Correlation Method
}

\author{
A. Henning, ${ }^{*}$ C. Spehr, ${ }^{\dagger}$ B. Wrede, ${ }^{\ddagger}$ R. Geisler,${ }^{\S}$ \\ M. Pott-Pollenske \\ German Aerospace Center (DLR), Göttingen, Germany
}

\begin{abstract}
The goal of the present paper is the experimental detection of noise sources at the leading edge slat in a high-lift device configuration. The noise generation mechanisms are experimentally investigated by means of pressure and velocity measurements in the nearfield and microphone measurements in the far-field. The measurements were conducted in a synchronized manner so as to enable the calculation of the cross-correlation between the acoustic pressure and the near-field fluctuations. The main idea of the concept presented here was to use the coefficient matrix obtained from the aforementioned correlation to identify regularities in the near-field fluctuations that are related to the radiated soundfield.
\end{abstract}

\section{Introduction}

The leading edge slat at high lift devices has been identified as a major contributor of airframe noise during aircraft approach and landing. ${ }^{1-3}$ It was found to be the source of tonal and broadband noise. Various noise generation mechanisms have been proposed. High-frequency tonal noise is caused by vortex shedding at the finite thickness trailing edge slat (trailing edge noise) ${ }^{4-6}$ Low-frequency noise is generated due to an interaction between the slat cove surface and the impinging shear layer. ${ }^{7-9}$ It is also proposed that a feedback mechanism between vortices from the slat trailing edge and vortices from the slat cusp acts as a resonator. ${ }^{10-12}$ In order to contribute to the understanding of the aeroacoustic source mechanism, surface pressure and Particle Image Velocimetry (PIV) measurements are conducted in the vicinity of the slat together with microphone-array measurements in the far-field. The measurements were synchronized so as to enable the calculation of the cross-correlation between the acoustic pressure and the near-field fluctuations. By this flow structures which are subject to the same physical phenomenon as the aeroacoustic sources are identified in a statistical manner. The technique relates the effect to the cause and hence is called a causality correlation. ${ }^{13}$ The causality correlation technique has been applied in the past by means of measuring the near-field fluctuations with various techniques. ${ }^{13-17}$ Recent experiments ${ }^{18-23}$ have shown that Particle-Image-Velocimetry (PIV) and microphone measurements can be used to obtain the cross correlation function between a near-field quantity and the acoustic pressure in the far-field. Using of the technique for the application orientated flow field around a slat presented here is the next step in the development of the causality correlation by means of PIV measurements in the near-field.

\footnotetext{
*Research Scientist, Technical University of Berlin, Institute for Aero- and Astronautics (ILR), Berlin, Germany. Current address: German Aerospace Center (DLR), Göttingen, Germany

${ }^{\dagger}$ Research Scientist, German Aerospace Center (DLR), Institute of Aerodynamics and Flow Technology (AS), Göttingen, Germany

${ }^{\ddagger}$ Diploma Student, German Aerospace Center (DLR), Institute AS, Göttingen, Germany

$\S$ Research Scientist, DLR, Institute AS, Göttingen, Germany

๑ Research Scientist, DLR, Institute AS, Braunschweig, Germany
} 


\section{Experimental Setup and Methods}

\section{A. Flow Configuration}

Experiments were conducted in the Aeroacoustic Wind Tunnel Braunschweig (AWB) of DLR, which is an open-jet closed-circuit anechoic test facility with a rectangular $0.8 \mathrm{~m}$ by $1.2 \mathrm{~m}$ nozzle exit. Measurements are performed on the DLR F16 model. It is a multi element 2D high-lift airfoil with a modular design. The model has already been used extensively in several common research projects at DLR in the past and several experimental and numerical results are available for comparison. ${ }^{24,25}$ In the present paper a 3 elements configuration is investigated. Figure 3 shows a sketch of the high-lift airfoil. The 2D model is installed between side plates with turntables, designed in prolongation of the nozzle. The model chord length is $c=300 \mathrm{~mm}$ (clean configuration) and the span measures $800 \mathrm{~mm}$. A parametric study is performed varying the deflection-angle, the slat -gap and -overlap as well as the flow speed $U_{\infty}$. For the selected configuration presented here, the deflection-angle $\delta$, gap $g$ and overlap ovl values for slat and flap are listed in Figure 2 normalized with the model chord. Measurements have been performed at free stream velocities $U_{\infty}=40 \mathrm{~m} / \mathrm{s}$ $\left(R e_{c}=800000\right), U_{\infty}=50 \mathrm{~m} / \mathrm{s}\left(R e_{c}=1000000\right)$ and $U_{\infty}=60 \mathrm{~m} / \mathrm{s}\left(R e_{c}=1200000\right)$ and $\alpha=11^{\circ}, 15.5^{\circ}$ and $19.5^{\circ}$ degrees incidence. In this experiment special slat-tracks on the suction side have been designed allowing the PIV camera to look inside the slat-cove (see Figure 3). Only results for $\alpha=11$ and $15.5^{\circ}$ at $U_{\infty}=50 \mathrm{~m} / \mathrm{s}$ are shown in the present paper.

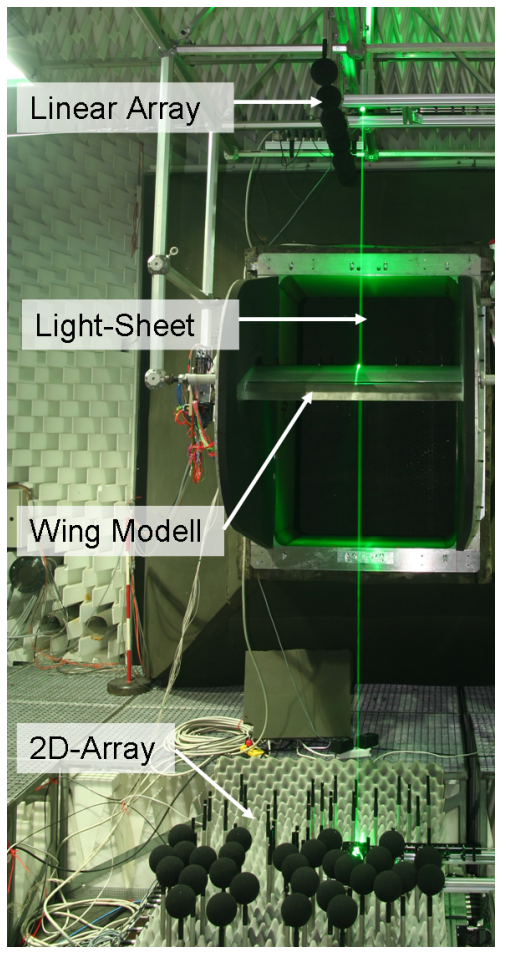

Figure 1. Picture of the experimental setup in the Aeroacoustic Wind Tunnel Braunschweig (AWB).

\begin{tabular}{|c|c|c|c|c|c|}
\hline$\delta_{s}$ & $g_{s}$ & ovl $_{s}$ & $\delta_{f}$ & $g_{f}$ & ovl \\
\hline \hline 27.834 & $2.27 \%$ & $1.07 \%$ & 35 & $2.11 \%$ & $0.56 \%$ \\
\hline
\end{tabular}

Figure 2. deflection-angle, gap and overlap values for slat $\left(\delta_{s}, g_{s}\right.$, $\left.o v l_{s}\right)$ and flap $\left(\delta_{f}, g_{f}, o v l_{f}\right)$ normalized with the model chord.

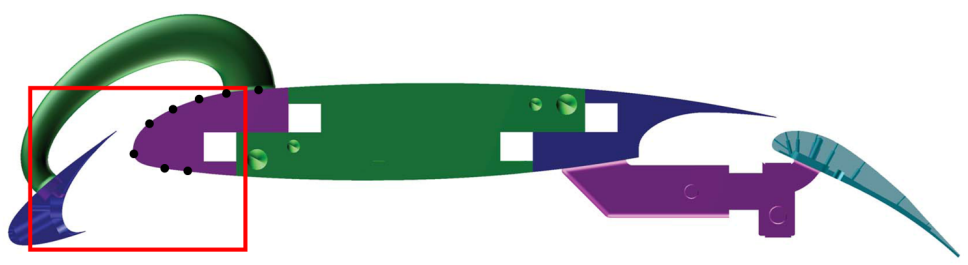

Figure 3. Cross sectional view of the F16 model. The span of the airfoil is $l=800 \mathrm{~mm}$. The box indicates the regions of interest (ROI) observed by the PIV camera. Black dots are indicating the positions of the pressure probes at the mid-span.

\section{B. PIV-Setup}

Velocity data are acquired with a two-dimensional PIV system, capable to capture two components of the velocity vectors in a plane. The system consists of a double-pulse laser system generating the light sheet and a camera (PCO.1600) recording the light scattered by the tracer particles. The frequency-doubled laser (Qswitched Nd:YAG; Quantel CFR 400) emits laser pulses with a maximum energy of $200 \mathrm{~mJ}$. It is operating at a repetition rate of $10 \mathrm{~Hz}$. The charge-coupled-device cameras have a resolution of $1600 \times 1000$ pixels and a frame rate of $5 \mathrm{~Hz}$ is used, which therefore represents the sampling rate of the whole PIV setup. To avoid 

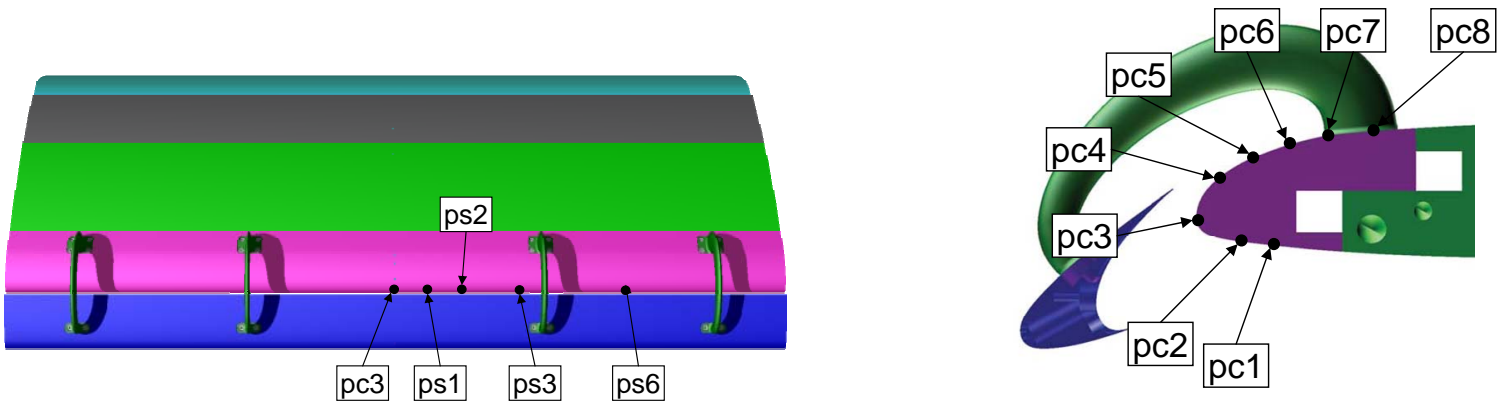

Figure 4. Position of the piezo-resistive pressure transducers arranged in spanwise (left) and chordwise (right) direction at the leading edge of the wing main-body. The chordwise distances of the sensors $p s 1-p s 6$ to the sensor $p c 3$ at the midspan position are $0.1 \mathbf{c} ; 0.2 \mathbf{c} ; 0.4 \mathbf{c}$; and $0.8 \mathbf{c}$ respectively.

shadowing effects, the slat region is illuminated from the top and the bottom of the model simultaneously. The resolution is $19.2 \mathrm{px} / \mathrm{mm}$ for the used cameras. By a visual inspection of the recorded particle images, the image size is observed to be in the range of $2-3$ pixels, which can probably be attributed to the lens aberrations and therewith the modulation transfer functions of the lens system used in the experiment. ${ }^{26}$ The observed particle image diameter implies that the influence of undersampling remains below an rms bias of 0.01 pixels. ${ }^{27}$ The flow is seeded with diethylhexylsebacate (DEHS) tracer particles with a mean particle diameter of approximately $1 \mu \mathrm{m} .{ }^{28}$ The seeding is injected from a corner of the wind tunnel upstream of the modell configuration in a way that the particles have to pass the complete wind tunnel before they reach the PIV field of view. The PIV and the pressure measurements are performed in a synchronized manner. In order to avoid a jitter between the PIV timing and the pressure data acquisition both measurement systems are synchronized by a master clock. The PIV data are processed using the PivView Software (see DLR contribution in Stanislas et al. ${ }^{29}$ ). A multi-grid algorithm ${ }^{26}$ with image deformation and sub-pixel interpolation $^{30}$ is used for the investigation presented here. The dynamic range was approximately $30 \mathrm{px}$ and the interrogation window size is $32 \times 32 \mathrm{px}$ with an overlap of $50 \%$.

\section{Surface Pressure Measurements}

Wall pressure fluctuations are measured with a set of pressure probes at the mid-span of the airfoil arranged in the chordwise direction at the leading edge of the wing main-body (see Figure 4 (right)). A second set of sensors is distributed in spanwise direction along the leading edge of the wing main-body (Figure 4 (left)). These probes are sub-miniature piezo-resistive pressure transducers. The sensors model is XQC-132A-093, manufactured by KULITE. The wiring of the sensor is shielded to reduce electrical noise. The nominal measurement range is $35 \mathrm{kPa}$. In order to operate the pressure transducers signal-conditioners model 436 manufactured by Endevco were used. The signal conditioners were installed altogether in the rack model 4990A also manufactured by Endevco. In the signal conditioners the voltage signals were pre-amplified. The gain factor was set to 100 during all the tests considered here. Since only unsteady pressure fluctuations were of interest an AC coupling of the signals was used. The analog signals were filtered, digitalized and recorded by the Viper data acquisition system used for the microphone signals with equal parameters.

\section{Far-Field Microphone Measurements}

A 2D-microphone array is located outside the flow-field below the high-lift device (pressure side). It consists of 64 microphones (M51 by LinearX). The distance between the model and the microphone membranes is approximately $-5.89 \mathrm{c}$ in the vertical $y$-direction. A linear microphone array is located above the model (suction-side) at a distance of approximately $3 \mathrm{c}$. It consists of 8 microphones. Figure 5 depicts the exact microphone-positions of the upper and lower array respectively. The microphone signals were simultaneously sampled with an A/D conversion of 16 bits at a sampling frequency of $f_{s}=100 \mathrm{kHz}$. All channels had an antialiasing filter at $f_{u}=50 \mathrm{kHz}$. To reduce the influence of low-frequency wind-tunnel noise on the measured signals a high-pass filter with a cutoff frequency $f_{l}=500 \mathrm{~Hz}$ has been applied. 

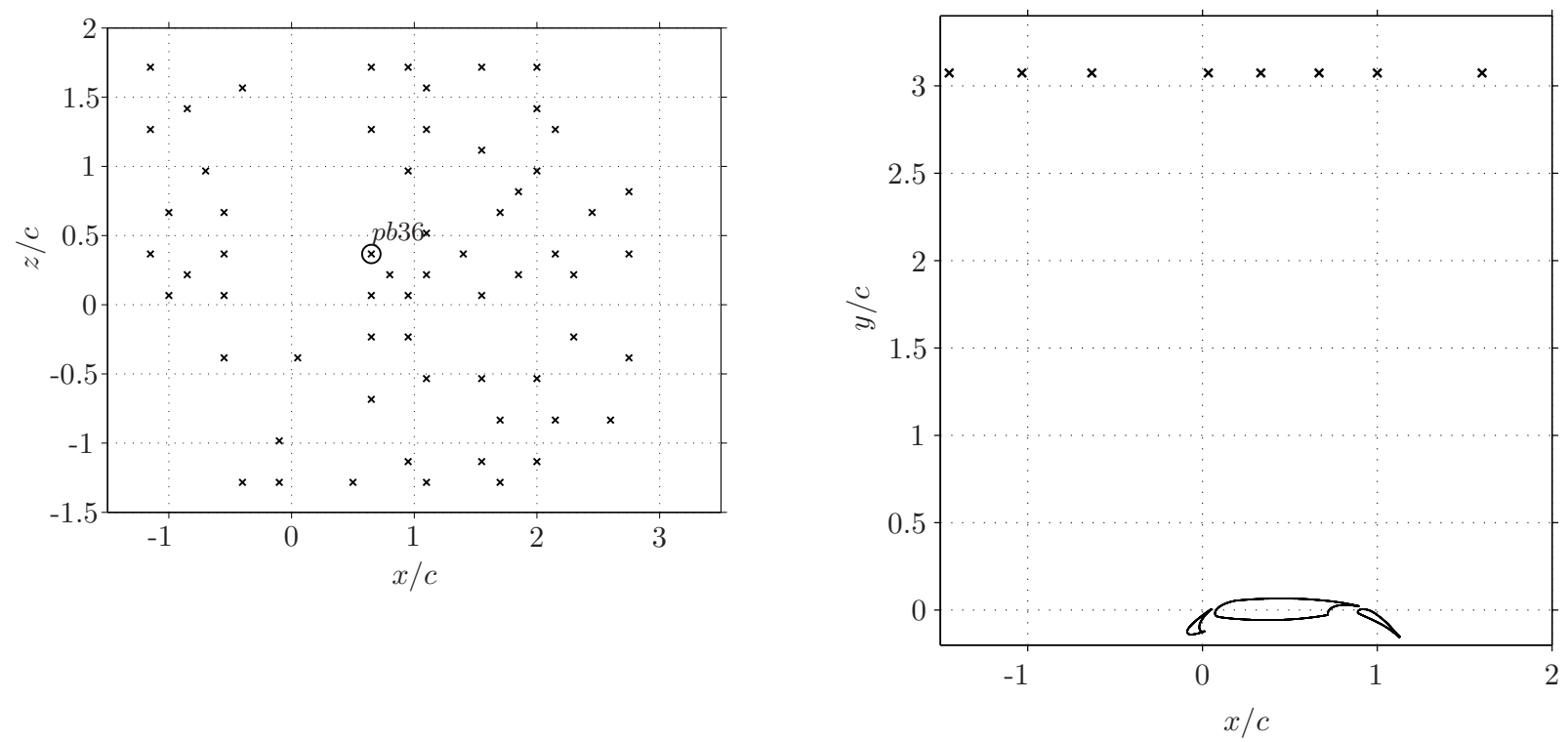

Figure 5. left Microphone-positions in the 2D-microphone array located outside the flow-field below the highlift device (pressure side). The Microphone used in the present paper is labeled and marked by a circle. The distance from the modell in the $y$-direction is $5.89 \mathrm{c}$ for all microphones. right Microphone-positions in the 1D-microphone array located outside the flow-field above the high-lift device (suction side). All microphones are located at midspan positions.

\section{E. Calculation of the cross correlation coefficient}

The sample correlation coefficient $R_{\psi, p}(\mathbf{x}, \tau)$ will be defined as

$$
R_{\psi, p}\left(\mathbf{x}, \tau^{\prime}\right)=\frac{S_{\psi, p}\left(\mathbf{x}, \tau^{\prime}\right)}{\sigma_{\psi}(\mathbf{x}) \sigma_{p}}=\frac{\left\langle\psi^{\prime}(\mathbf{x}, t) p^{\prime}\left(t+\tau^{\prime}\right)\right\rangle}{\sqrt{\left\langle\psi^{\prime}(\mathbf{x}, t)^{2}\right\rangle\left\langle p^{\prime}(t)^{2}\right\rangle}}
$$

where $\psi^{\prime}(\mathbf{x}, t)$ represents the zero-mean part of a near-field quantity $\psi$ measured at position $\mathbf{x}$ and time $t$. The variable $\tau^{\prime}$ is the time shift between the pressure signal and $\psi$. The correlation coefficient is normalized by the root-mean-square (RMS) values of $\psi^{\prime}$ and $p^{\prime}$ which are denoted by $\sigma_{\psi}(\mathbf{x})$ and $\sigma_{p}$.

\section{Results and Discussion}

The axes in the following figures are scaled to the chord $c=300 \mathrm{~mm} . x$ and $y$ are right-handed Cartesian coordinates with the origin at leading edge of the clean wing configuration. The local coordinate system of the wing is used in the following illustrations.

\section{A. Flowfield}

Averaged velocity vector maps for the selected configurations are depicted in Figure 6. For the purpose of clarity only every second vector is plotted. The velocities are made dimensionless using the free stream velocity $U_{\infty}$. Flow patterns typically observed in the vicinity of a slat can be observed in the figures as described in the literature: ${ }^{11,32}$

- The development of a shear layer from the separation at the slat-cusp.

- The recirculation region in the slat-cove.

- The acceleration of the flow in the slat-gap near the leading edge of the main element.

The main difference between the selected configurations lies in the path of the shear layer emanating from the slat-cusp. In comparison, the curvature is greater in case of $\alpha=15.5^{\circ}$, resulting in a smaller recirculation 
region and a reattachment point further upstream. It is known from the literature that this shear layer emanating from the slat-cusp with high values of positive sign vorticity, breaks up into discrete vortices. It impinges on the slat-cove wall and vortices either got ejected through the slat-gap or trapped inside the recirculation area in the slat-cove. Previous studies have shown that such coherent flow structures have a strong influence on the correlation coefficients between the the near- and far-field data. Their topology and extensions are important for an interpretation of the temporal as well as the spatial coefficient distribution presented in section C. ${ }^{31}$ In order to give an impression of the regularity in the coherent structures, the autocorrelation of the vertical velocity component will be shown in the following. The spatial correlations are calculated using the Pearson product-moment correlation defined as:

$$
R_{\Phi_{i}, \Phi_{j}}\left(\mathbf{x}_{R}, \mathbf{x}\right)=\frac{\left\langle\Phi_{i}^{\prime}\left(\mathbf{x}_{R}\right) \Phi_{j}^{\prime}(\mathbf{x})\right\rangle}{\sigma_{\Phi_{i}}\left(\mathbf{x}_{R}\right) \sigma_{\Phi_{j}}(\mathbf{x})}
$$

The coefficients $R_{v, v}$ for the respective reference points $\mathbf{x}_{R}=[x / c ; y / c]=[0.053 ;-0.055]$ and $[x / c ; y / c]=$ $[0.05 ;-0.049]$ are depicted in Figure 7 . The choice of these reference points is motivated by the fact, that at these positions the correlation between the velocity fluctuations and the far-field pressure is the highest (see section C). Significant coefficients can be observed in the whole investigated region for both configurations. The location of local maxima and minima in the proximity of the reference points can be explained by the spatial coherence caused by the vortices emanating from the slat-cusp. The values of these local extrema are observed to be higher in the left figure. Therefore it can be assumed that the large scale vortices are showing a different behavior in case of the lower angle of attack. This can be either a stronger periodicity of these structures in the shear layer or a difference in the size and strength of the vortices.
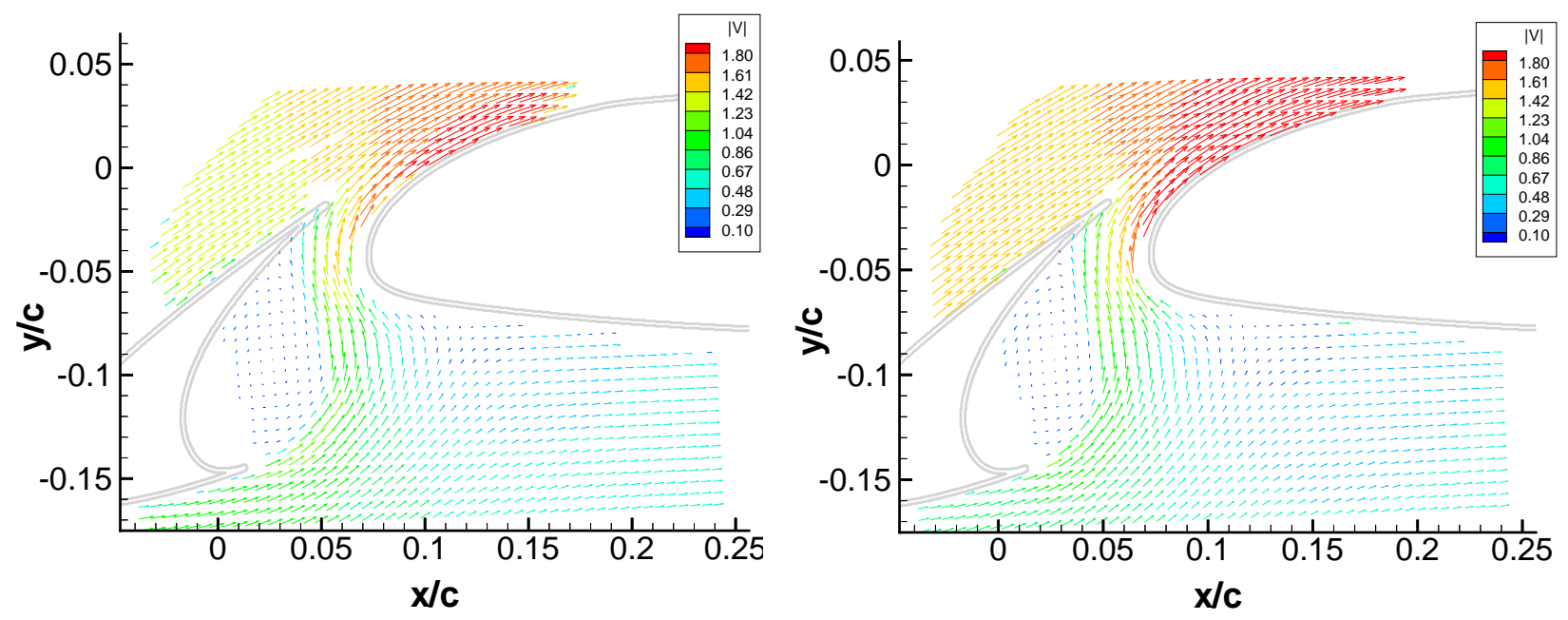

Figure 6. Averaged velocity vector maps at $U_{\infty}=50 \mathrm{~m} / \mathrm{s}$ for $\alpha=11$ (left) and $\alpha=15.5^{\circ}$ (right). Every second vector has been omitted for clarity. 

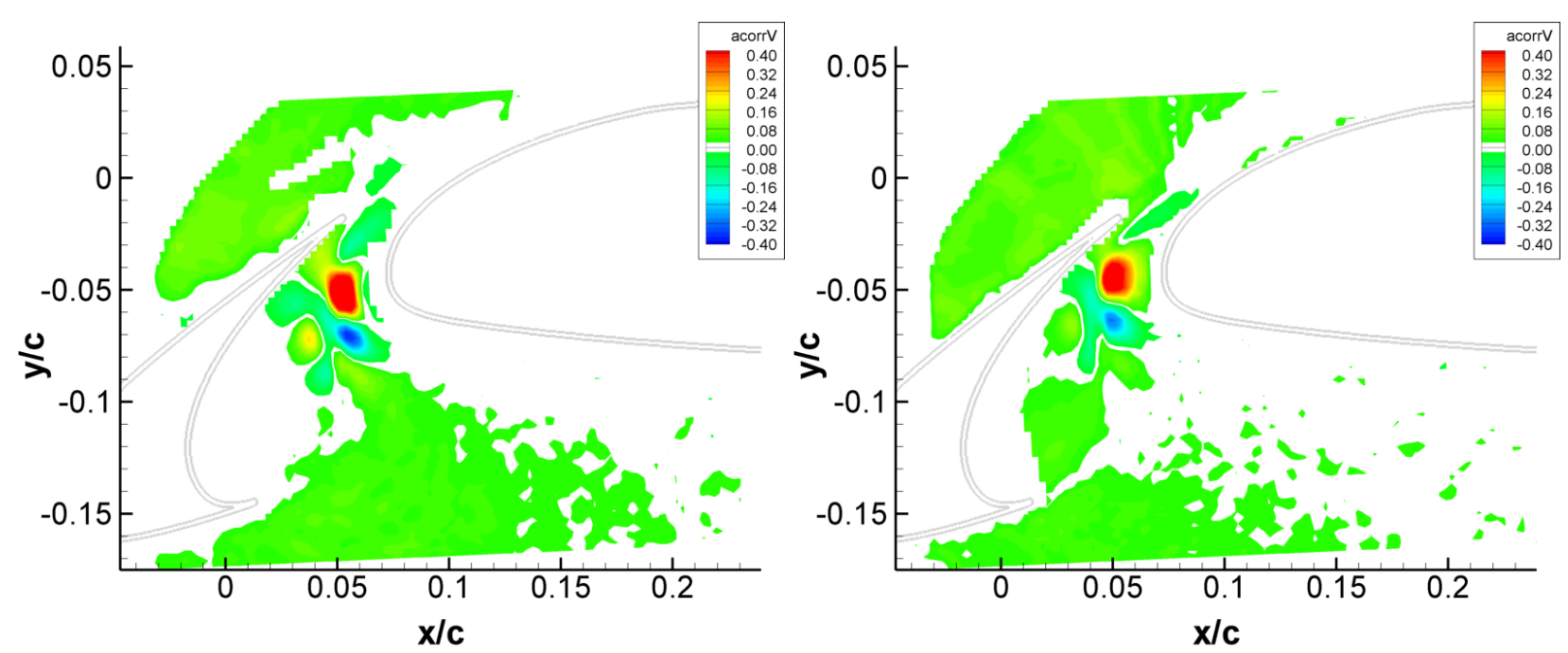

Figure 7. The autocorrelation of the vertical velocity component $R_{v, v}$ for $\alpha=11$ (left) and $\alpha=15.5^{\circ}$ (right). The reference points are $[x / c ; y / c]=[0.053 ;-0.055]$ and $[x / c ; y / c]=[0.05 ;-0.049]$ respectively.

\section{B. Acoustic Results}

Acoustic frequency spectra are calculated with a number of 600 averages using a Hanning window and a total averaging period of $30 \mathrm{~s}$. The frequency resolution is $10 \mathrm{~Hz}$. Sound pressure levels (SPL) are given in $\mathrm{dB}$ with a reference pressure of $p_{\text {ref }}=2 \cdot 10^{-5} \mathrm{~Pa}$. A set of spectra for the selected configurations with $U_{\infty}=50 \mathrm{~m} / \mathrm{s}$ is depicted in Figure 8 (left), measured at a single microphone pb36 (see Figure 5) of the $2 \mathrm{D}$-Array located at $90^{\circ}$ to the flow direction at $x / c \approx 0.5$ (pressure side). The main difference between the two configurations is the presence of stronger tonal components in case of the lower angle of attack. Here, high peaks in the far-field spectrum can be observed at approximately 1900, 2300 and $3100 \mathrm{~Hz}$. These local maxima are also present in Figure 8 (right) showing the frequency distribution of pressure fluctuations measured at the piezo-resistive pressure transducer $p c 3$, located at the leading edge of the wing main-body near the stagnation point.
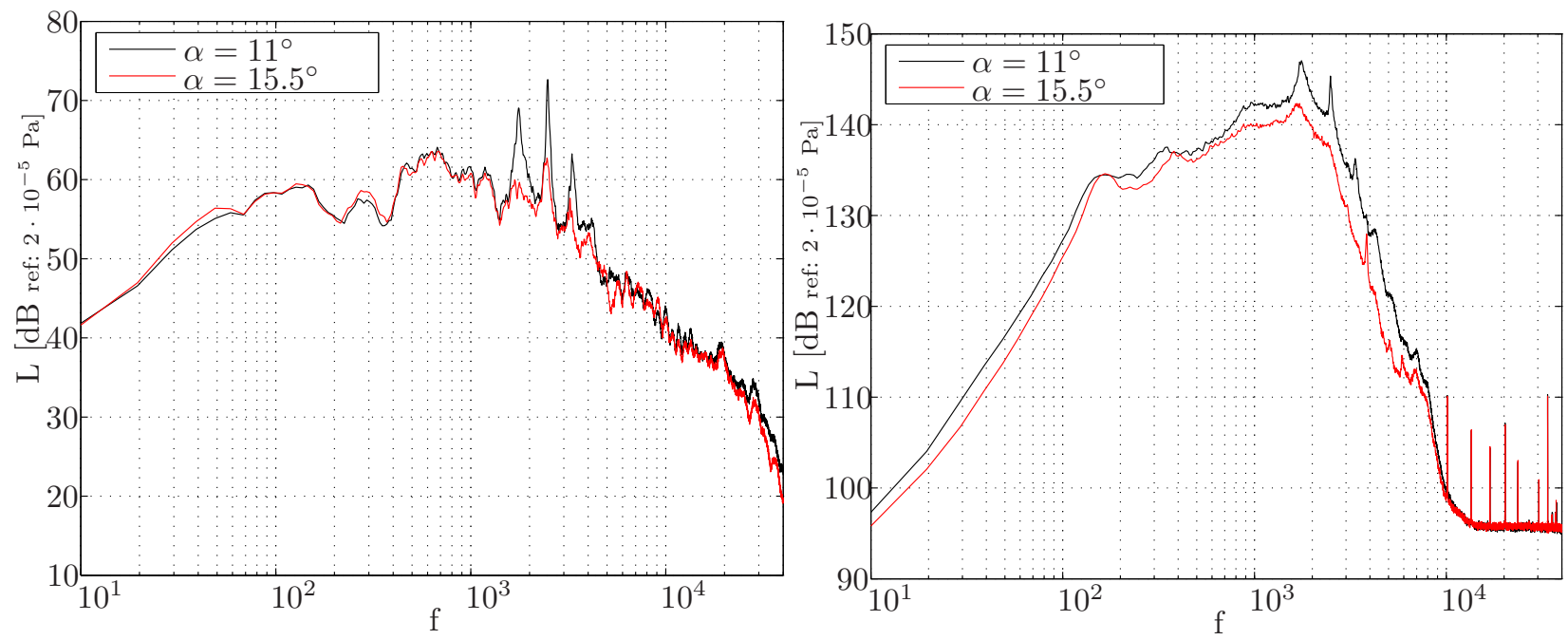

Figure 8. Comparison of sound pressure levels for the different configurations with $U_{\infty}=50 \mathrm{~m} / \mathrm{s}$. left: Measured at a single microphone pb36 (see Figure 5) of the 2D-Array located at $90^{\circ}$ to the flow direction at $x / c \approx 0.5$ (pressure side). right: Measured at the piezo-resistive pressure transducer pc3 at the leading edge of the wing main-body near the stagnation point. 

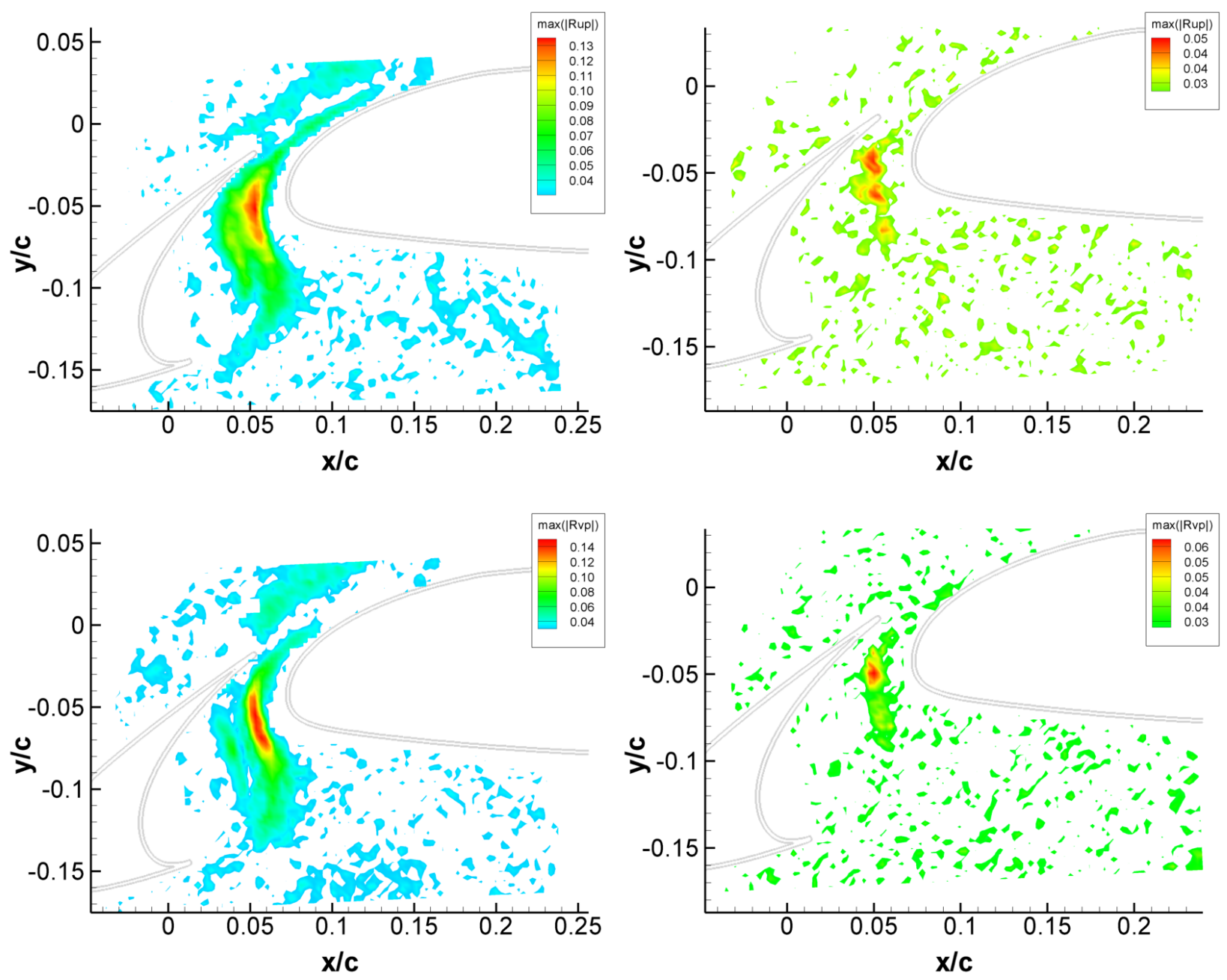

Figure 9. Spatial distribution of the maximum coefficient values $\max _{\tau}\left(\left|R_{u, p}(\mathbf{x}, \tau)\right|\right)($ top $)$ and $\max _{\tau}\left(\left|R_{v, p}(\mathbf{x}, \tau)\right|\right)$ (bottom) observed at the two selected configurations with $\alpha=11$ (left) and $\alpha=15.5^{\circ}$ ( right) at $U_{\infty}=50 \mathrm{~m} / \mathrm{s}$.

\section{Cross-Correlation Results}

16000 PIV snapshots are considered for the comparison of the cross-correlation results; this number corresponds to the maximum number available for all investigated configurations. Note that the final error margin for $R_{\psi, p}$ with 16000 samples is approximately \pm 0.02 based on a $t$ test against zero (99\% probability). For the purpose of clarity, levels lower than the error margin are not shown in the correlation distributions. Note that $\tau=\tau^{\prime}-r / c_{0}$ is the retarded time shift. $r$ is the distance from the measurement point in the flow field to the microphone and $c_{0}=341 \mathrm{~m} / \mathrm{s}$ is the defined ambient sound speed. In the results shown in the following, $p$ is the pressure fluctuation measured at a single microphone of the $2 \mathrm{D}$-Array located at $90^{\circ}$ to the flow direction at $x / c \approx 0$ (pressure side).

Figure 9 shows the maximum values of the cross correlation coefficient $\max _{\tau}\left(\left|R_{v, p}\right|\right)$ with respect to $\tau$ observed at two selected configurations with $\alpha=11^{\circ}$ and $\alpha=15.5^{\circ}$ at $U_{\infty}=50 \mathrm{~m} / \mathrm{s}$. Due to shadowing effects an area containing no data can be found in the lower slat cavity. In case of $\alpha=11^{\circ}$ the regions of significant values are distributed around a curved path from the slat-cusp to the slat-gap and further downstream along the suction side of the airfoil. The path corresponds to the region where the free shear layer emanates from the slat-cusp. In case of $\alpha=15.5^{\circ}$ the region of significant values is smaller and limited to an area at the beginning of the slat-gap.

The temporal evolutions of the cross-correlation coefficients $R_{v, p}$ are depicted in Figure 10 for both con- 
figurations at positions where the overall maxima of the correlation-coefficients are observed in Figure 9. In case of $\alpha=11^{\circ}$ the temporal evolution of $R_{v, p}$ shows a strong periodicity with a maximum value at $\tau=0$. The spatial distribution of this coefficient shows a certain order, which is similar to the topologies of the autocorrelation coefficient $R_{v, v}$. Previous studies have shown, that in case of periodic structures in the flow field and tonal components in the far-field pressure fluctuations, the correlation between the velocity fluctuations and the acoustic pressure shows the same oscillations as the input signals. In section A it was found that the coherent structures are more pronounced in case of the smaller angle of incidence $\alpha=11^{\circ}$. In addition, the tonal components in the acoustic spectrum are much more pronounced in the case of the lower angle of attack. This is different in case of $\alpha=15.5^{\circ}$ where the correlation function shows only a relatively short event which consists mainly of a single positive and negative deflection.

It should be noted that the location of maximum values of $R_{v, p}$ alone cannot be interpreted as the origins of aeroacoustic sources. ${ }^{23}$ But the coherent structures in the flow are part of the same physical process which causes the pressure fluctuations in the far field. There exists a linear relationship between the fluctuations in this area and those in the field of actual sound generation, which in turn is linearly related to the pressure fluctuations in the far field. Therefore, high values of the coefficients $R_{v, p}$ can be seen in areas which are not causally related to the sound generation, but are strongly influenced by the vortices emanating from the slat-cusp. Figure 12 shows a time series of the instantaneous distribution of the cross-correlation coefficient
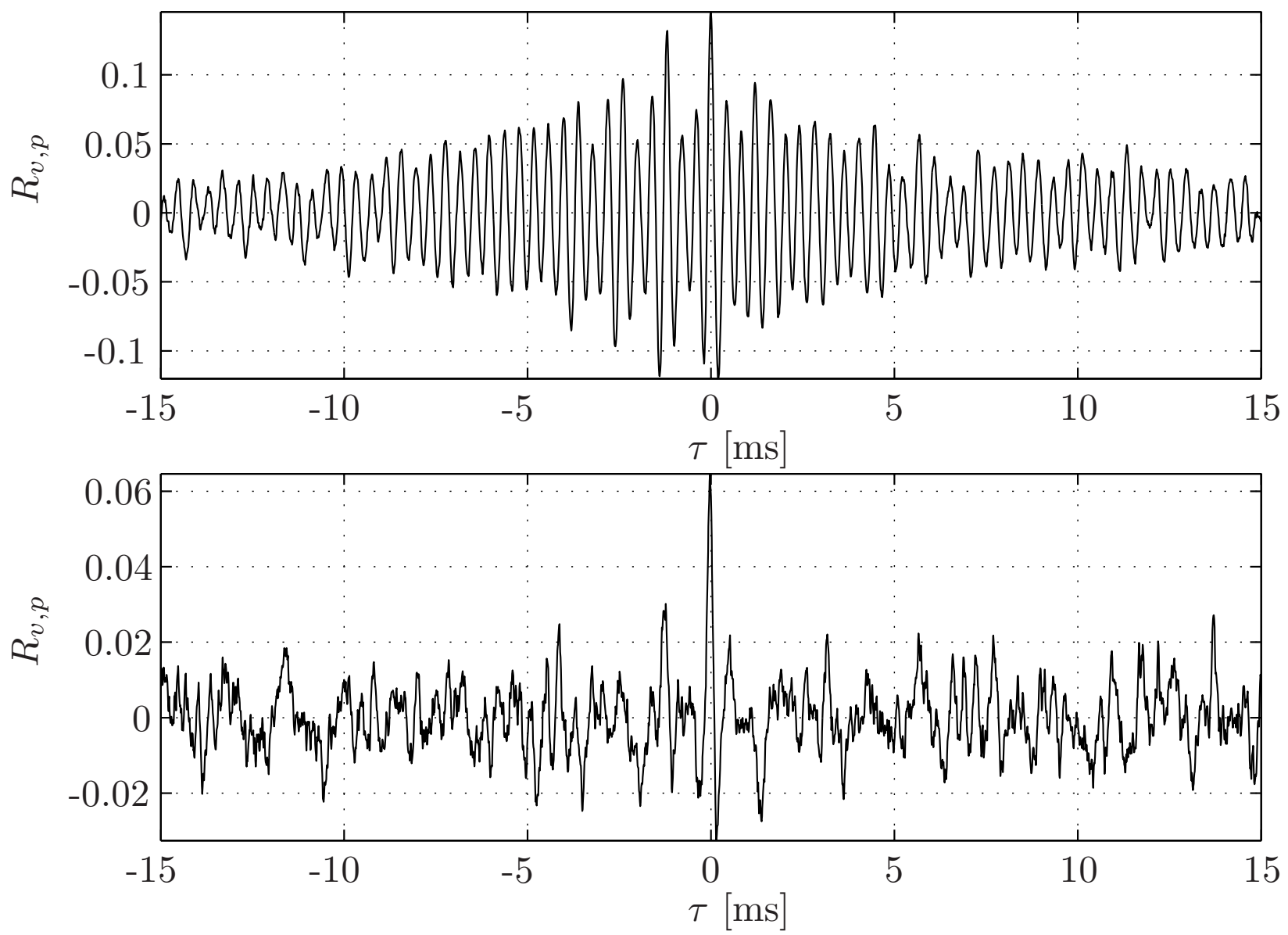

Figure 10. Temporal evolution of the cross-correlation coefficients $R_{v, p}$ for the two selected configurations with $\alpha=11$ (top) and $\alpha=15.5^{\circ}\left(\right.$ bottom) at $U_{\infty}=50 \mathrm{~m} / \mathrm{s}$. The evolution is depicted for the positions $[x / c ; y / c]=$ $[0.053 ;-0.055]$ and $[x / c ; y / c]=[0.05 ;-0.049]$ respecively, where the overall maxima of the correlation-coefficients $R_{v, p}$ are observed in Figure 9.

$R_{v, p}$ at $\tau=0.4,0.2 \ldots-0.6 \mathrm{~ms}$ for the case $\alpha=11^{\circ}$. Regular patterns of significant positive and negative values can be identified along the described trajectory of the shear layer. These periodic pattern corresponds to the periodicity observed in the temporal evolution of the coefficient shown in Figure 10. Further investi- 
gations are necessary to assess the complete sound source mechanisms of the configuration presented here. By an analysis of the temporal evolution of maximum correlation values it should be possible to show how these coherent structures in the flow, together with the tonal components of the far-field pressure signals, are linked to the resulting spacial and temporal evolution of the coefficient-matrix. The correlation between the surface pressure signals and flow quantities as well as far-field pressure signals will provide additional information about the sound generation process.
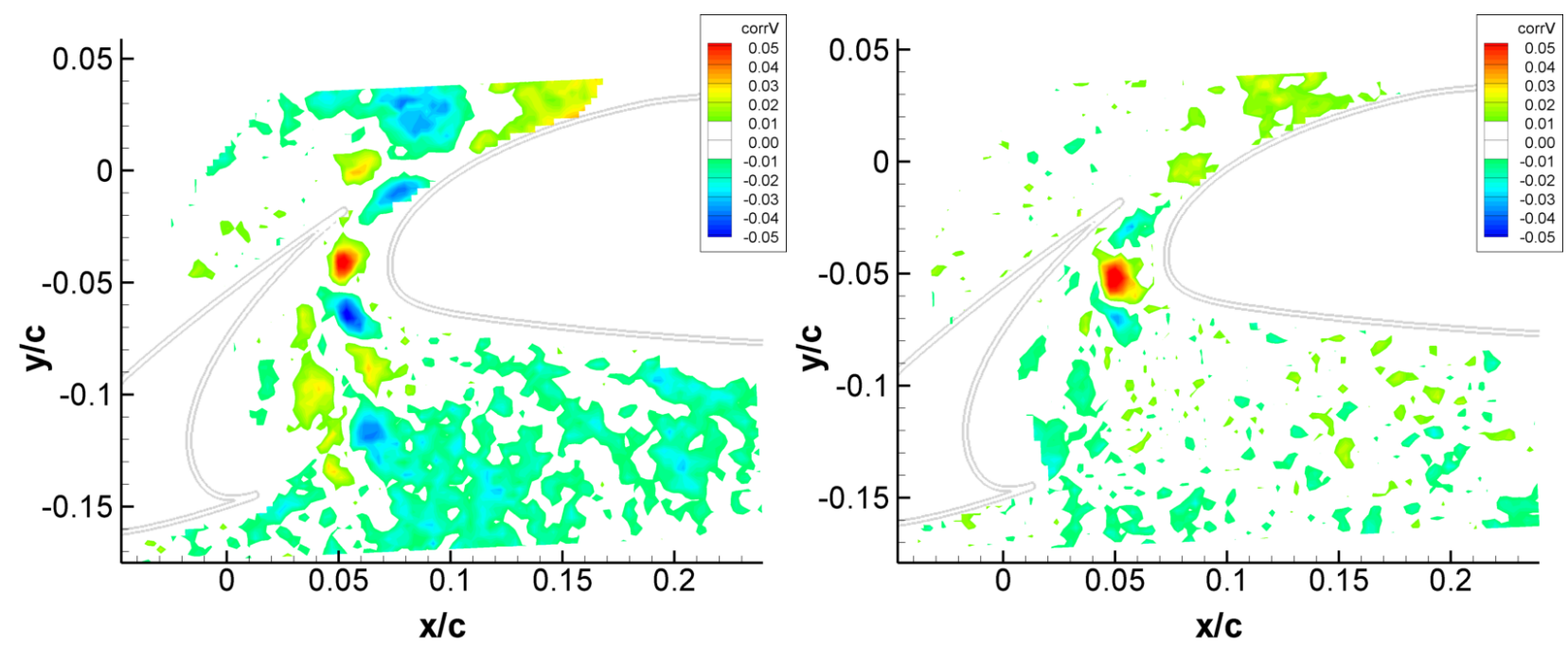

Figure 11. Spatial distribution of the cross-correlation coefficients $R_{v, p}$ at $\tau=0$ for the two selected configurations with $\alpha=11$ (left) and $\alpha=15.5^{\circ}$ (right) at $U_{\infty}=50 \mathrm{~m} / \mathrm{s}$. 

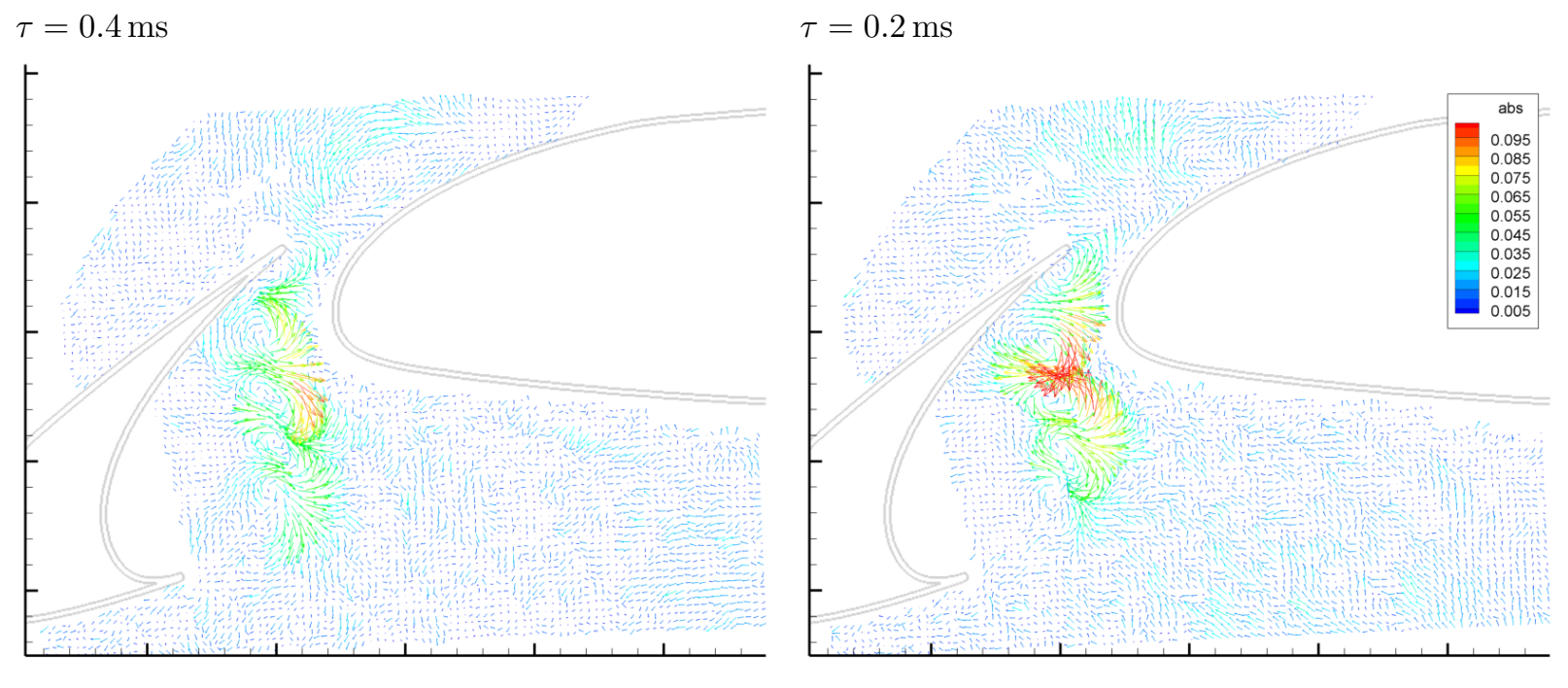

$\tau=0 \mathrm{~ms}$

$\tau=-0.2 \mathrm{~ms}$
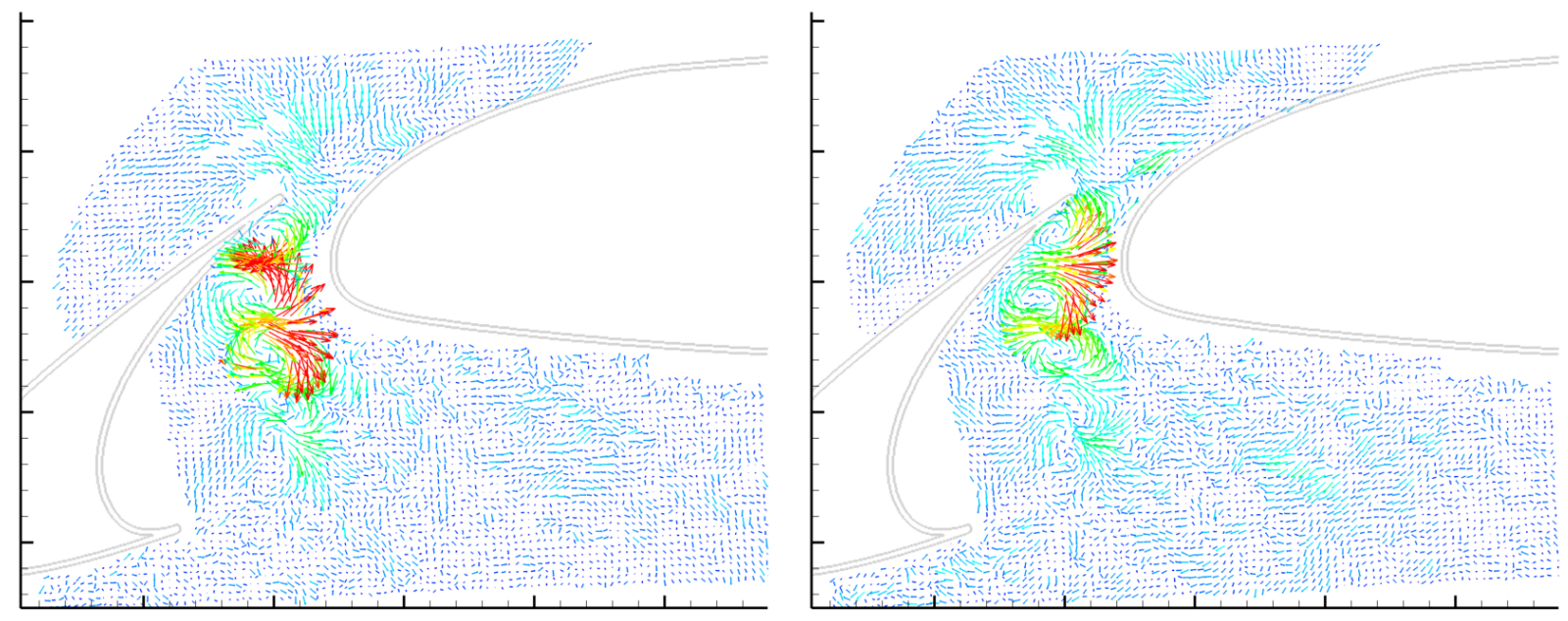

$\tau=-0.4 \mathrm{~ms}$

$\tau=-0.6 \mathrm{~ms}$
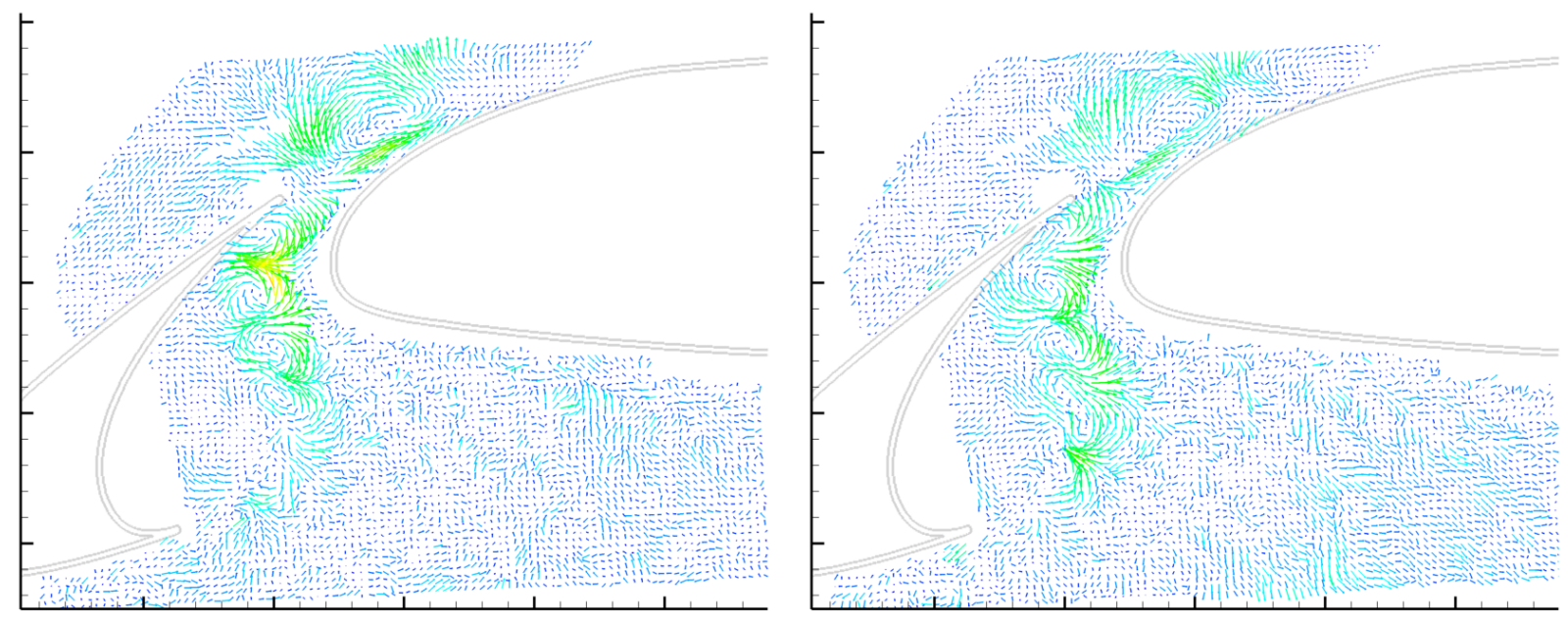

Figure 12. $\alpha=11$ at $U_{\infty}=50 \mathrm{~m} / \mathrm{s}$. Time series of the instantaneous distribution of the cross-correlation coefficient $R_{v, p}$ for $\tau=0.4,0.2 \ldots-0.6 \mathrm{~ms}$ (row-major order). See Figure 9 for coordinates. 


\section{Conclusion}

The noise sources at the leading edge slat in the DLR F16 high-lift device configuration are investigated by means of the causality correlation method. The cross-correlation between the acoustic far-field pressure and near-field fluctuations obtained via particle image velocimetry (PIV) is calculated. A parametric study is performed varying the deflection-angle, the slat -gap and -overlap as well as the flow speed $U_{\infty}$. The results for 2 selected configurations are shown in the study presented here. In case of a shallow deflection-angle the temporal evolution of the correlation $R_{v, p}$ between the far-field pressure $p$ and the vertical velocity component $v$ shows a strong periodicity. The temporal evolution together with the spatial distribution of the coefficient corresponds to a regular pattern of discrete vortices emanating from the slat-cusp and being accelerated and ejected through the slat-gap. Thus these coherent structures can be identified as part of the sound generation process. For a higher deflection-angle very similar flow structures are present in the slat-cove region. But here only a comparatively small region of significant correlation values can be identified. This corresponding single positive and negative deflection in the temporal evolution of the correlation function is typical for a source process with a broadband characteristic. The results show that a parameter change can be directly assigned to a change of flow structures which are part of the sound generation process by means of the proposed causality correlation method.

\section{References}

${ }^{1}$ Michel, U., Barsikow, B., Helbig, J., Hellmig, M., and Schttpelz, M., "Flyover Noise Measurements on a Landing Aircraft with a Microphone Array," 4th AIAA/CEAS Aeroacoustics Conference, No. AIAA-Paper 98-2336, Toulouse, France, 1998.

${ }^{2}$ Piet, J., Michel, U., and Bhning, P., "Localization of the Acoustic Sources of the A340 with a Large Phased Microphone Array During Flight Tests," AIAA Paper, Vol. 2002-2506, 2002. 2004.

${ }^{3}$ Oerlemans, S. and Sijtsma, P., "coustic Array Measurements of a 1:10.6 Scaled Airbus A340 Model," Vol. 2004-2924,

${ }^{4}$ Singer, B., Lockard, D., and Khorrami, M., "Computational Aeroacoustic Analysis of Slat Trailing-Edge Flow," AIAA Paper, Vol. 99-1802, 1999.

${ }^{5}$ Khorrami, M. and Choudhari, M., "Application of Passive Porous Treatment to Slat Trailing Edge Noise," NASA/TM, Vol. 2003-212416, 2003.

${ }^{6}$ Khorrami, M., Choudhari, M., Singer, B., Lockard, D., and Streett, C., "In Search of the Physics: The Interplay of Experiment and Computation in Slat Aeroacoustics," AIAA Paper, Vol. 2003-0980, 2003.

${ }^{7}$ Jenkins, L., Khorrami, M., and Choudhari, M., "Characterization of Unsteady Flow Structures Near Leading-Edge Slat: Part I-PIV Measurements," AIAA Paper, Vol. 2004-2801, 2004.

${ }^{8}$ Takeda, K., Ashcroft, G., Zhang, X., and Nelson, P. A., "Unsteady Aerodynamics of Slat Cove Flow in a High-Lift Configuration," AIAA Paper, Vol. 2001-0706, 2001.

${ }^{9}$ Khorrami, M., Singer, B., and Berkman, M., "Time-Accurate Simulations and Acoustic Analysis of Slat Free-Shear Layer," AIAA Paper, Vol. 2001-2155, 2001.

${ }^{10}$ Storms, B., Hayes, J., Moriarty, P., and Ross, J., "Aeroacoustic Measurements of Slat Noise on a Three-Dimensional High-Lift System," AIAA Paper, Vol. 99-1957, 1999.

${ }^{11}$ Takeda, K., Zhang, X., and Nelson, P. A., "Unsteady Aerodynamics and Aeroacoustics of a High-Lift Device Configuration," AIAA Paper, Vol. 2002-0570, 2002.

${ }^{12}$ Olsen, S., Thomas, F., and Nelson, R., "A Preliminary Investigation into Slat Noise Production Mechanisms in a High-Lift Configuration," AIAA Paper, Vol. 2000-4508, 2000.

${ }^{13}$ Rackl, R. and Siddon, T. E., "Causality correlation analysis of flow noise with fluid dilatation as source fluctuation," Vol. 65, No. 5, 1979, pp. 1147-1155.

${ }^{14}$ Lee, H. K. and Ribner, H. S., "Direct correlation of noise and flow of a jet," Vol. 52, No. 5, 1972, pp. 1280-1290.

${ }^{15}$ Schaffar, M., "Direct measurement of the correlation between axial in-jet velocity fluctuations and far field noise near the axis of a cold jet," J. Sound Vib., Vol. 64, No. 1, 1979, pp. 73-83.

${ }^{16}$ Panda, J. and Seasholtz, R. G., "Experimental investigation of density fluctuations in high-speed jets and correlation with generated noise," J. Fluid Mech., Vol. 450, Jan. 2002, pp. 97-130.

${ }^{17}$ Picard, C. and Delville, J., "Pressure velocity coupling in a subsonic round jet," Int. J. Heat and Fluid Flow, Vol. 21, No. 3, June 2000, pp. 359-364.

${ }^{18}$ Schröder, A., Kompenhans, J., Engler, R., and Goldhahn, E., Current Topics in Experimental Transonic Aerodynamics, VKI LS 2005-01, von Karman Institute for Fluid Dynamics, 2005, pp. 1 - 23.

${ }^{19}$ Nakano, T., Fujisawa, N., and Lee, S., "Measurement of tonal-noise characteristics and periodic flow structure around NACA0018 airfoil," Experiments in Fluids, Vol. 40, 2006, pp. 482-490.

${ }^{20}$ Henning, A. and Ehrenfried, K., "On the accuracy of one-point and two-point statistics measured via high-speed PIV," 14th Int. Symp. on Appl. of Laser Techn. to Fluid Mechanics., Lisbon, Portugal, 2008.

${ }^{21}$ Nashimoto, A., Fujisawa, N., Nakano, T., and Yoda, T., "Visualization of Aerodynamic Noise Source around a Rotating Fan Blade," Journal of Visualization, Vol. 1, No. 4, 2008, pp. 365-373. 
${ }^{22}$ Henning, A., Koop, L., Ehrenfried, K., Kröber, S., and Spehr, C., "Anwendung der Particle-Image-Velocimetry für akustische und aeroakustische Untersuchungen," DAGA 2010 36. Jahrestagung für Akustik, No. 000361 in CD-ROM Tagungsband, 2010, pp. 335-336.

${ }^{23}$ Henning, A., Schroeder, A., Koop, L., and Agocs, J., "Causality Correlation Analysis on a Cold Jet by Means of Simultaneous PIV and Microphone Measurements," 6th AIAA/CEAS Aeroacoustics Conference, Vol. AiAA-2010-3753, Stockholm (Sweden), 2010.

${ }^{24}$ Ewert, R., Dierke, J., Siebert, J., Neifeld, A., Appel, C., Siefert, M., and Kornow, O., "CAA broadband noise prediction for aeroacoustic design," Journal of Sound and Vibration, Vol. 330, No. 17, 2011, pp. 4139 - 4160, jce:title¿COMPUTATIONAL AERO-ACOUSTICS (CAA) FOR AIRCRAFT NOISE PREDICTION PART Bi/ce:title

${ }^{25}$ Ewert, R., Dierke, J., Appel, C., Pott-Pollenske, M., and Sutcliffe, M., "CAA-RPM prediction and validation of slat setting influence on broadband high-lift noise generation," 2010.

${ }^{26}$ Raffel, M., Willert, C. E., Wereley, S. T., and Kompenhans, J., Particle Image Velocimetry - A Practical Guide, Springer, 2nd ed., 2007.

${ }^{27}$ Nobach, H., Damaschke, N., and Tropea, C., "High-Precision Sub-Pixel Interpolation In Particle Image Velocimetry Image Processing," Experiments in Fluids, Vol. 39, 2005, pp. 299 - 304.

${ }^{28}$ Kähler, C. J., "General design and operating rules for seeding atomisers," 5th International Symposium on Particle Image Velocimety, Busan, Korea, September 22-24, September 22-24 2003.

${ }^{29}$ Stanislas, M., Okamoto, K., Kähler, C. J., and Westerweel, J., "Main results of the Second International PIV Challenge," Experiments in Fluids, Vol. 39, No. 2, 2005, pp. 170 - 191.

${ }^{30}$ Scarano, F., "Iterative image deformation methods in PIV," Meas. Sci. Technol., Vol. 13, 2002, pp. R1 - R19.

${ }^{31}$ Henning, A., Koop, L., Ehrenfried, K., Lauterbach, A., and Kroeber, S., "Simultaneous Multiplane PIV and Microphone Array Measurements on a Rod-Airfoil Configuration," 15th AIAA/CEAS Aeroacoustics Conference, Vol. AIAA-2009-3184, Miami (USA), 2009.

${ }^{32}$ Choudhari, M., Lockard, D., Macaraeg, M., Singer, B., Streett, C., Neubert, G., Stoker, R., Underbrink, J., Berkman, M., Khorrami, M., and Sadowski, S., "Aeroacoustic Experiments in the Langley Low-Turbulence Pressure Tunnel," NASA/TM 2002-211432, Feb 2002. 